\title{
Effect of Gas Bubbling Filtration Treatment on Microporosity Variation in A356 Aluminium Alloy
}

\author{
Choongdo Lee ${ }^{1} \cdot$ Taeil So $^{2} \cdot$ Kwangseon Shin ${ }^{2}$
}

Received: 8 January 2016/Revised: 18 April 2016/Published online: 26 May 2016

(C) The Chinese Society for Metals and Springer-Verlag Berlin Heidelberg 2016

\begin{abstract}
In the present study, the contribution of the gas bubbling filtration (GBF) process to the microporosity variation, microstructural characteristics and tensile properties of A356 aluminium alloy was investigated. The test specimens were fabricated through gravity casting in terms of the process variables: the degassing time, the impeller rotation and the aperture size of gas inlet hole. The density measurement and scanning electron microscope fractography analyses were conducted to evaluate the variation of the volumetric porosity and fractographic porosity with the GBF process, respectively. The fractographic porosity of the specimens can be minimised under specific GBF conditions in terms of the buoyant velocity and the absorbing capacity of gas bubbles, the inclusion of oxide films, whereas the volumetric porosity can be wholly reduced on the lapse of degassing time. The ultimate tensile strength (UTS) and elongation at optimal conditions were improved to approximately $30 \mathrm{MPa}$ and $1.5 \%$ compared with no GBF treatment. Even though an extension of the degassing time and/or excessive stirring action of the melt may induce the inclusion of bifilm oxides and the increase of fractographic porosity, the tensile properties of over-treated specimens were maintained to a level which is similar to those that did not undergo GBF treatment due to the grain refinement accompanying with the GBF process. In addition, the defect susceptibility of UTS and elongation to microporosity variation could be remarkably improved at an optimal GBF condition.
\end{abstract}

\section{KEY WORDS: Aluminium alloy; Microporosity; Gas bubbling filtration process (GBF); Tensile property}

\section{Introduction}

As useful light alloys for weight reduction, the aluminium alloys-produced through various casting process-have been widely used in various structural components in the

Available online at http://link.springer.com/journal/40195

Choongdo Lee

cdlee@inhatc.ac.kr

1 Department of Metallurgical \& Materials Engineering, Inha Technical College, 100 Inha-ro, Nam-gu, Incheon 402-752, Korea

2 Magnesium Technology Innovation Center, Department of Materials Science and Engineering, Seoul National University, 1 Gwanak-ro, Gwanak-gu, Seoul 151-744, Korea transportation industry. As well known, the mechanical properties of Al-Si series alloys depend not only on the metallurgical factors such as microstructural characteristics and chemical composition, but also on manufacturing variables such as cooling rate and melt treatment [1]. In terms of the load-carrying capacity inside a casting, it is recognised that the casting defects such as micro-voids and inclusions play a significant role in deteriorating the mechanical properties [1]. The formation of the casting defects is intimately related to manufacturing variables such as the melt control and solidification process. Therefore, the degassing treatment on the melting and holding process has been recognised as a typical method of controlling the production quality of aluminium castings [1-9]. The main reason for the formation of micro-voids in aluminium alloy casting is generally considered as the 
difference between hydrogen solubility and the volumetric shrinkage during solid/liquid transformation. The volumetric shrinkage can be minimised by controlling the solidification rate and by improving the feeding efficiency of liquid phase. However, the void formation due to the difference in hydrogen solubility between the solid and liquid phases can be controlled by melt treatments such as GBF [2-6], vacuum and inert gas atmosphere [7], degassing agent [8] and ultrasonication [9]. Among them, the GBF treatment can provide an obvious effect on the reduction of porosity, minimising the melt loss and dross formation even for simple production variables on conventional casting processes such as high-pressure and lowpressure die-casting [3].

Several previous studies reported that the overall level of microporosity in aluminium cast alloys is decreased with GBF time, and the degassing treatment using a porous bartype lance and the rotary-type impeller has a higher efficiency than that using a single bar-type lance $[1-6,12]$. However, the excessive rotation of the rotary-type impeller can in fact remarkably degrade the mechanical properties of the alloy by the inclusion of bifilm oxide particle and dross into the melt [3,10-12]. These results are easily explained by the basic principles of GBF process, in terms of the variation of absorbing capacity due to the duration time in a melt and the size distribution of the gas bubbles. Nevertheless, the dependence of the mechanical properties on microporosity variation in the GBF process is still unclear, and systematic studies have been rarely conducted on the contribution of GBF variables in terms of the defect susceptibility of tensile properties to microporosity variation.

In the present study, we investigated the relationship between the microporosity and the tensile properties of A356 aluminium alloy and aimed to clarify the optimal GBF conditions that minimise the defect susceptibility of the tensile properties due to microporosity variation.

\section{Experimental}

\subsection{Specimen Preparation}

The raw material used in the present study was an $\mathrm{Al}-$ $7 \% \mathrm{Si}-0.4 \% \mathrm{Mg}$ alloy; its typical chemical composition is listed in Table 1 . The raw material was melted in a graphite crucible using a high-frequency induction furnace and then

Table 1 Chemical composition of A356 aluminium alloys

\begin{tabular}{llllllll}
\hline $\mathrm{Si}$ & $\mathrm{Mg}$ & $\mathrm{Mn}$ & $\mathrm{Cu}$ & $\mathrm{Fe}$ & $\mathrm{Ti}$ & $\mathrm{Sr}$ & $\mathrm{Al}$ \\
\hline 7.3 & 0.33 & 0.055 & 0.09 & 0.291 & 0.053 & 0.02 & $\mathrm{Bal}$ \\
\hline
\end{tabular}

transferred to an electric resistance furnace for GBF treatment. The holding temperature for the GBF treatment was about $720{ }^{\circ} \mathrm{C}$, and after a completed GBF treatment, a melt surface was mechanically skimmed and stabilised over $3 \mathrm{~min}$. With the stabilisation, the holding temperature of a melt was controlled at $730{ }^{\circ} \mathrm{C}$ and finally poured into a multi-step metallic mould (width is $120 \mathrm{~mm}$, thickness is $5-25 \mathrm{~mm}$, length is $50 \mathrm{~mm}$ per thickness) heated to approximately $300{ }^{\circ} \mathrm{C}$.

The degassing treatment was conducted using the disctype impeller $(40 \mathrm{~mm}$ in diameter) stainless steel (304 series) which has four gas inlet holes (1 and $2 \mathrm{~mm}$ in diameter) as shown in Fig. 1, and the melt was degassed by Ar gas $[0.5 \mathrm{~L} /(\mathrm{kg} \mathrm{min})]$ up to $15 \mathrm{~min}$. The test specimens were fabricated with regard to the degassing time, the size variation of the gas inlet hole and the rotation speed of the impeller, and were gathered from a section of $15 \mathrm{~mm}$ thickness in a metallic mould.

\subsection{Microstructural Observation and XRD Analysis}

The test specimen for microstructural analysis was obtained from the centre position of a section in a mould, and the etchant used was a Keller-type solution $(2 \% \mathrm{HF}+3 \%$ $\mathrm{HCl}+5 \% \quad \mathrm{HNO}_{3}+$ distilled water). As a typical microstructural feature indicating the grain refinement of the GBF process, the grain size and the secondary dendrite arm spacing (SDAS) were measured via the intercept line method. The microstructural analysis was based upon 5 views (over 10 intercept lines per a view) on each GBF condition, and the microstructural change on GBF treatment such as the area fraction and circularity of eutectic Si particles was evaluated via 2-colour image analysis.
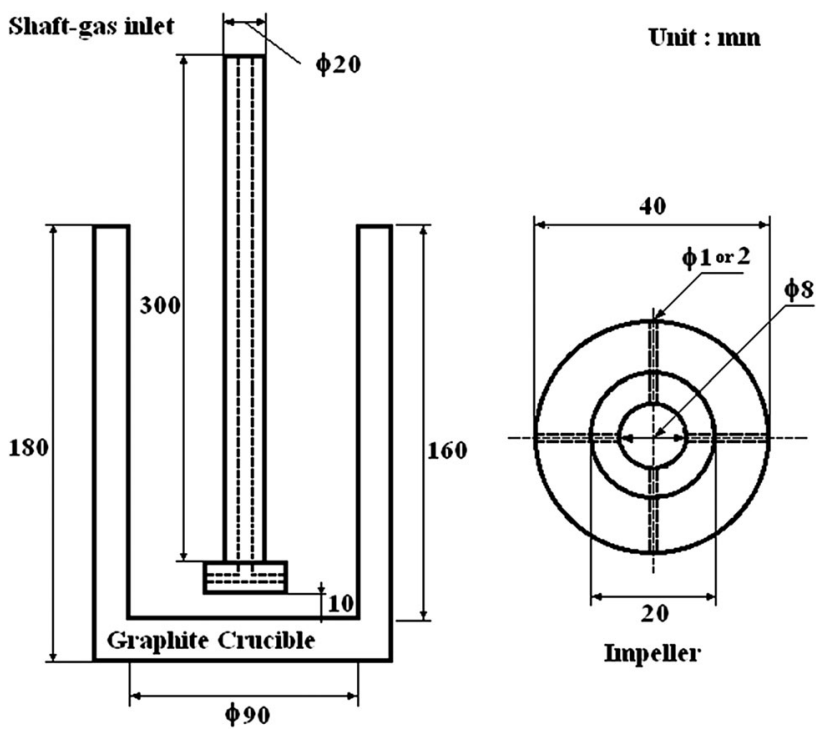

Fig. 1 Dimensions of crucible and impeller used for melt treatment 
Additionally, the fractured surfaces were analysed using $\mathrm{X}$-ray diffraction (XRD, Bruker Miller, D8-Advance), for investigating the existence of bifilm oxides on the fractured surface. The XRD analyses were conducted with a scan speed of $5 \% \mathrm{~min}$, a diffraction angle of $20^{\circ}-80^{\circ}$ and $\mathrm{Cu}$ filtration at an acceleration voltage of $30 \mathrm{kV}$.

\subsection{Tensile Test and Measurement of Microporosity}

The tensile specimen was fabricated as a round type with a gauge length of $20 \mathrm{~mm}$ and a diameter of $4 \mathrm{~mm}$, and the tension test was carried out with a universal test machine (Instron 5585 model) at room temperature, under strain rate conditions of $2.8 \times 10^{-4} \mathrm{~s}^{-1}$ using an extensometer. For each GBF condition, the tensile specimens were fabricated over 6 pieces.

The microporosity of the test specimen was evaluated by the volumetric porosity and fractographic porosity terms. The volumetric porosity was measured by calculating the bulk density of tensile specimens using the Archimedes method (Toyoseiki, Densimeter-H). And, the fractographic porosity was measured by quantitative fractography analysis based on SEM (JEOL/JSM-5600, Oxford/INCA) observations. The fractographic porosity was expressed as the area fraction of the micro-voids and oxide films to the entire area of the fracture surface.

\section{Experimental Results}

\subsection{Microstructural Characteristics}

Figure 2 shows the typical views for the transition of microstructural features through GBF treatment. As shown, the size distribution of the pro-eutectic Al matrix and eutectic $\mathrm{Si}$ particles is observed. It is noted that the interspacing of eutectic $\mathrm{Si}$ particles is remarkably decreased through GBF treatment. The dependence of microstructural features such as the grain size and SDAS upon the degassing time is shown in Fig. 3 and Table 2. As shown, the average value of the grain size and SDAS decreases from 225 and $41 \mu \mathrm{m}$ with no degassing to approximately 180 and $20 \mu \mathrm{m}$ by 15 -min degassing treatment. And, the grain size and SDAS on degassing condition with $1-\mathrm{mm}$ aperture size show slightly lower values than those of 2-mm aperture size.

\subsection{Porosity Variation}

Figure 4 shows the variation of the volumetric porosity with the degassing time and the aperture size. It shows that the volumetric porosity decreases from $3.5 \%$ for no degassing to about $2.5 \%$ as the degassing time increases to $5 \mathrm{~min}$, but there is little dependence of volumetric porosity on the aperture size of the gas inlet. And, the volumetric porosity slightly decreases from $2.5 \%$ of 5 -min GBF treatment to about $2.0 \%$ over 15 -min degassing treatment.

Figure 5 shows the variation of fractographic porosity with the degassing time and the aperture size. It shows that the fractographic porosity when degassed with gas inlet holes of 2-mm aperture size decreases to about $5.0 \%$ for a degassing treatment of just $5 \mathrm{~min}$, whereas when degassed with $1-\mathrm{mm}$ holes, the porosity abruptly increases to about $30 \%$ for 10-min degassing treatment. This is in opposition to the forecast that the absorbing ability of the gas bubbles may be increased by decreasing the size of the gas bubbles formed with a smaller gas inlet hole. And, the result means that the agglomeration of micro-voids during solidification process may be practically controlled under these conditions, with the inclusion of bifilm oxides promoted by turbulent circulation inside the melt.
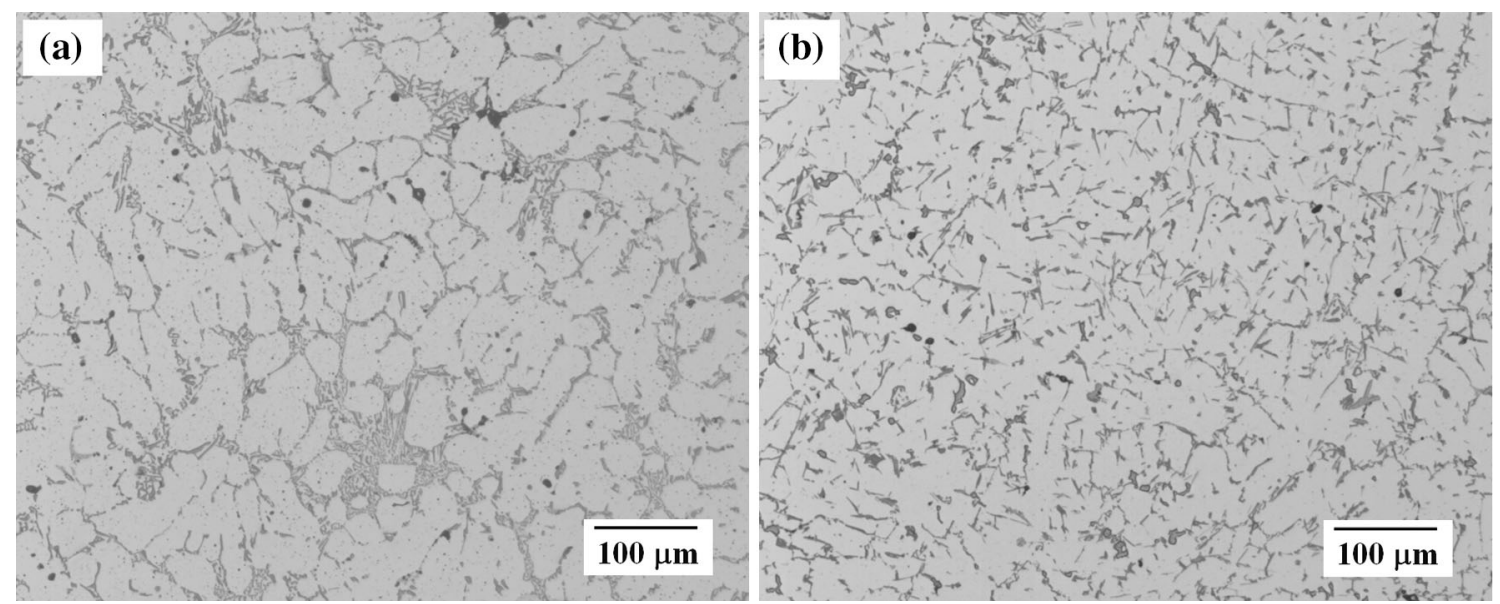

Fig. 2 Typical microstructural views of gravity-casted A356 alloys after GBF treatment; a no degassing and b 5-min degassing treatment 


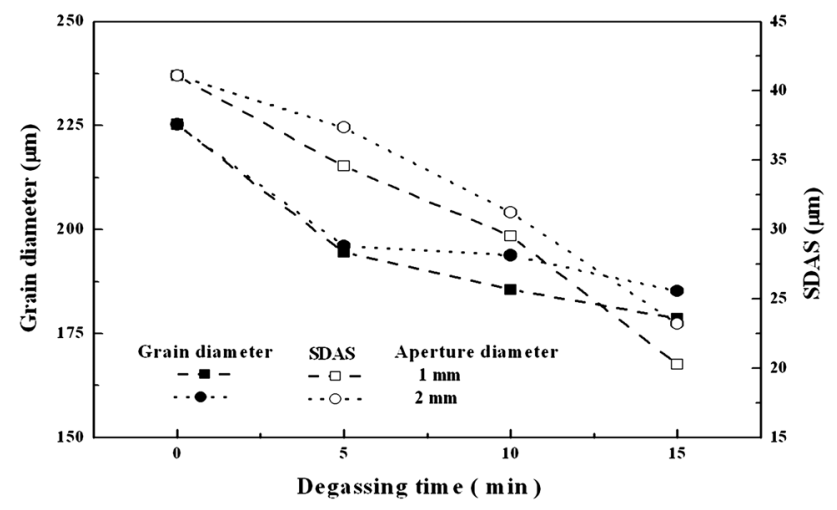

Fig. 3 Average SDAS value with the lapse of degassing time for GBF treatment of A356 alloy

\subsection{Tensile Properties}

Figure 6 shows the variation of the tensile strength and elongation with the degassing time under different size of gas inlet holes. In the case of $1 \mathrm{~mm}$ diameter, the tensile properties are remarkably improved with degassing time of 5 min, i.e. the yield strength and UTS increase from 103 and $170 \mathrm{MPa}$ to 116 and $195 \mathrm{MPa}$, respectively, and the tensile elongation increases from $2.1 \%$ of no GBF condition to $2.5 \%$. However, the tensile properties degrade similarly to that under no degassing as the degassing time increases over $5 \mathrm{~min}$. In particular, the tensile elongation at degassing time over $10 \mathrm{~min}$ essentially deteriorates to a level lower than that under no degassing, whereas the UTS is maintained on the level similar to that under no degassing.

In contrast, Fig. $6 \mathrm{~b}$ shows that the tensile properties of the samples treated with 2-mm-diameter aperture are practically improved by the use of the degassing treatment. As shown, the UTS and elongation are increased to approximately $204 \mathrm{MPa}$ and $4.1 \%$, respectively, compared with $170 \mathrm{MPa}$ and $2.1 \%$ of no degassing condition. From this, it can note that the optimal conditions for improving

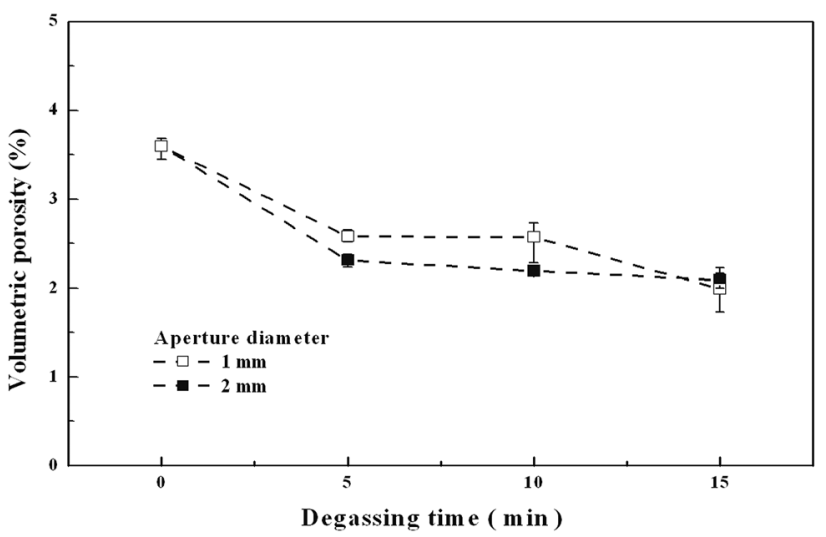

Fig. 4 Variation of volumetric porosity with the degassing time

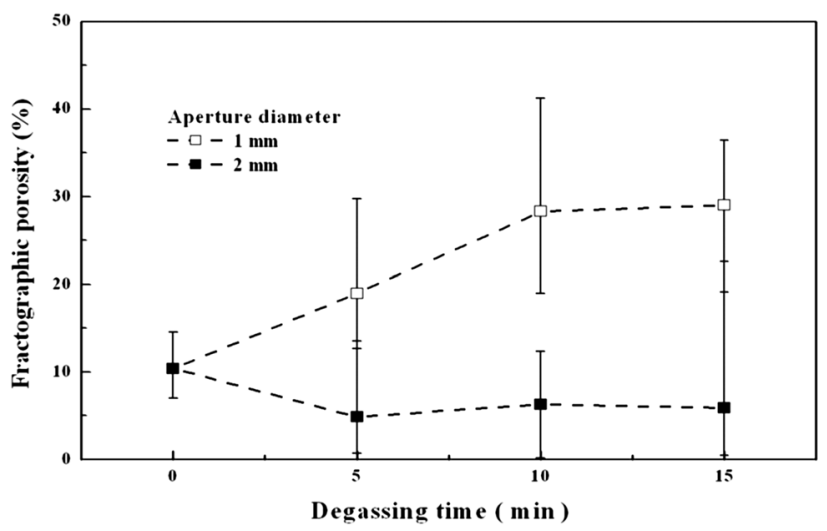

Fig. 5 Variation of fractographic porosity measured in the tensile fractured surface on degassing time

the tensile properties of the sample undergoing degassing depend upon the aperture size of the gas inlet, i.e. the size of formed bubbles and the stirring action of a melt. In addition, it can confirm that the tensile properties are fundamentally related to the overall level of fractographic porosity, and not to the variation of the volumetric porosity.

Table 2 Typical values for microstructural change on GBF treatment

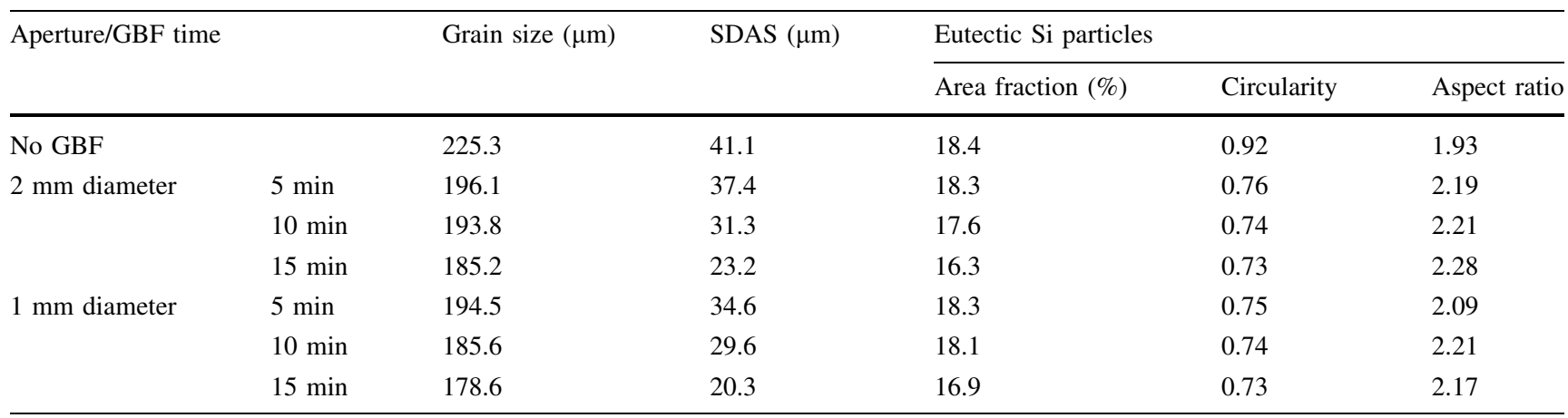



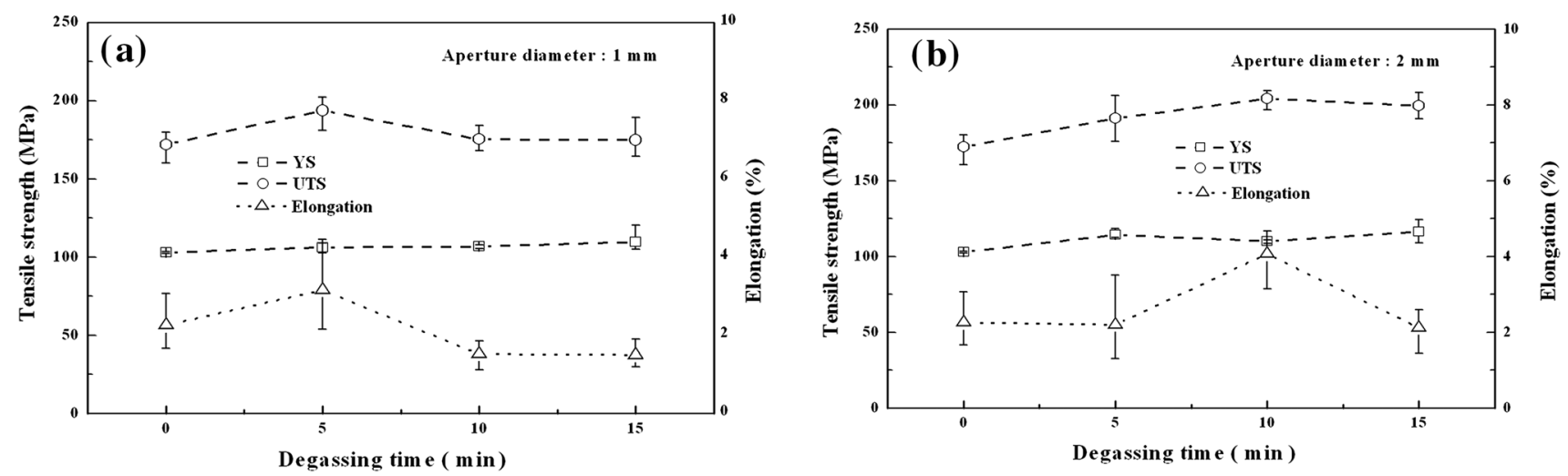

Fig. 6 Variation of tensile strength and elongation with the degassing time under difference aperture sizes of the gas inlet of $1 \mathrm{~mm}$ diameter $\mathbf{a}$ and $2 \mathrm{~mm}$ diameter $\mathbf{b}$

However, Fig. 6 indicates that the yield strength steadily increases with the degassing time. Typically, the yield strength for the samples treated with a gas inlet hole of $2 \mathrm{~mm}$ diameter is improved from approximately 100 to $115 \mathrm{MPa}$ with degassing treatment. The main reason for the improvement of the yield strength is attributed to the microstructural refinement such as the size distribution of eutectic Si particle and the interspacing between Si particles shown in Fig. 3 and Table 2. Thus, the degassing time of 5 and 10 min with the corresponding impeller diameters of 1 and $2 \mathrm{~mm}$ can be suggested as the optimal parameters for GBF treatment in terms of the microporosity variation and the nominal level of tensile properties.

Figure $7 a-c$ shows the SEM images of fractured surfaces without GBF treatment, and Fig. 7d shows the 10-min GBF-treated alloy with impeller of 2-mm-diameter aperture. In Fig. $7 \mathrm{a}$, the typically fractured appearance without GBF treatment is characterised by a roughly indented fractured morphology which is composed of a cluster of shrinkage cavities formed during the solidification process (as magnified in Fig. 7b) and bifilm oxide inclusions (as magnified in Fig. 7c). Figure 7e, f shows typical results of EDS analysis from the A- and B-positions shown in Fig. 7a, respectively, indicating the inclusions at B-position are the oxides. The fractured morphology transitions to a fine-faceted morphology due to the grain refinement and the removal of oxide inclusion could be obtained by optimal GBF treatment as shown in Fig. 7d.

Figure 8 shows the contributions of melt stirring and size control of the gas bubbles to the overall level of microporosity and the tensile properties. Figure 8 a shows that the fractographic porosity is dependent upon the rotation of the impeller, whereas the volumetric porosity does not vary in any practical sense with the rotation speed. In addition, Fig. $8 \mathrm{~b}$ indicates that the tensile properties of GBF-treated alloys depend practically upon the variation of fractographic porosity.

\subsection{Defect Susceptibility}

The defect susceptibility has been suggested for the quantitative description of the dependence of the tensile properties on microporosity variation by Gokhale et al. [13-16]. Figure 9 shows the variability of the defect susceptibility of UTS and elongation with the microporosity variation under GBF treatment. And, the nominal values for the defect susceptibility of the tensile properties to microporosity variation and the maximum values of the tensile properties achievable under defect-free conditions are listed in Table 3.

Under optimal GBF treatment conditions, the defect susceptibility of the tensile properties is remarkably improved, comparing with no GBF treatment. In addition, the maximum tensile properties under defect-free conditions increased with the increase of the strain-hardening exponent that occurs as a result of GBF treatment.

\section{Discussion}

\subsection{Optimal GBF Conditions for Bubble Size and Buoyancy}

The absorption capacity of dissolved hydrogen gas in an aluminium melt depends upon the surface area of the gas bubbles formed by the GBF treatment. Given that the total surface area of the gas bubbles decreases with an inverse relationship to the square root of the bubble size, the absorption capacity of dissolved hydrogen gas under GBF treatment can be improved by the increase of degassing time and the reduction of bubble size. In addition, the buoyant speed of gas bubbles to the surface of the melt should be minimised in order to maximise the degassing efficiency by increasing the time the gas bubbles remain in the melt. The buoyant speed of the gas bubbles is mainly 

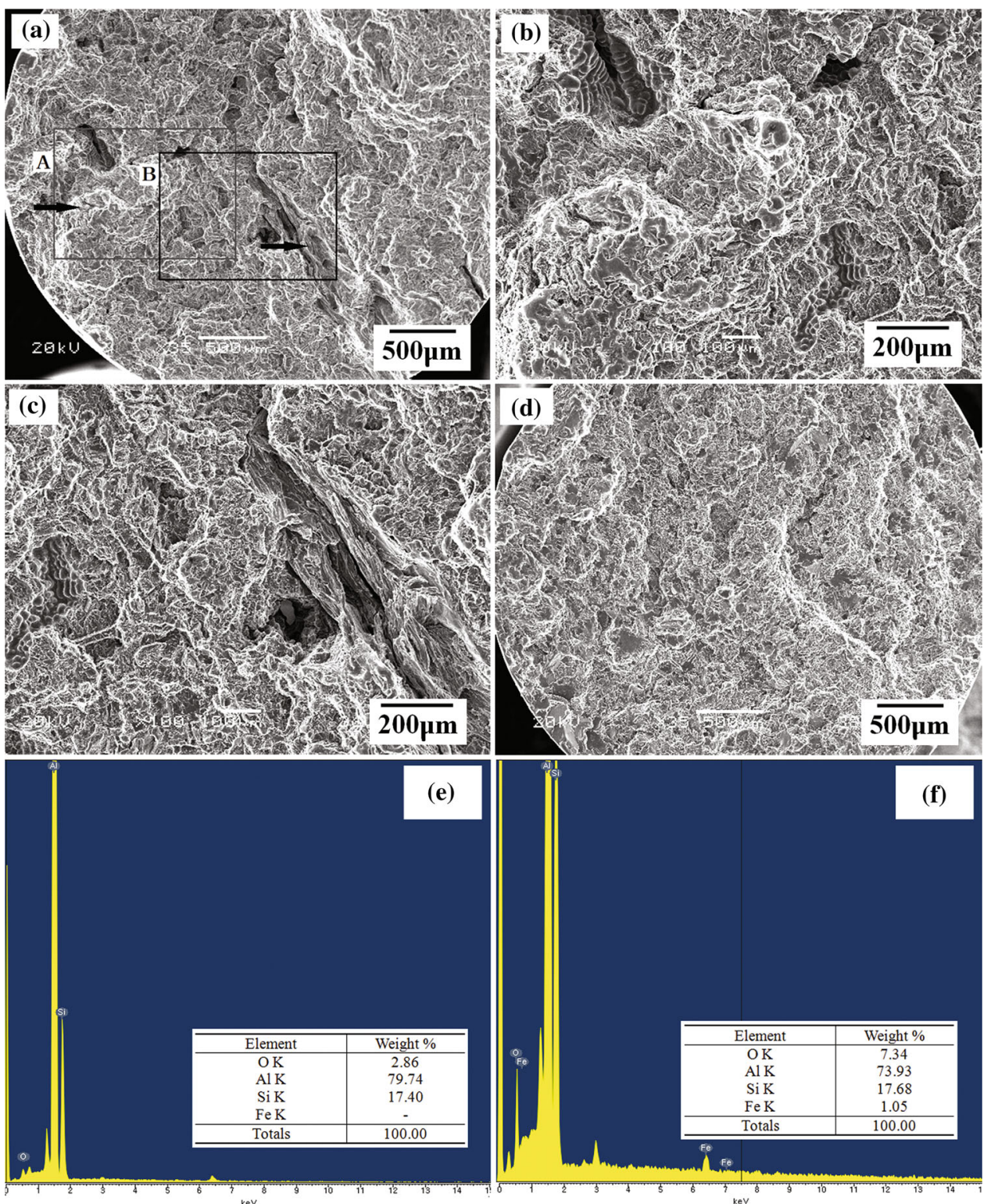

Fig. 7 SEM images of the fractured specimens; no GBF a, high magnification $\mathbf{b}$, $\mathbf{c}$ for $A$ - and $B$-positions in $\mathbf{a}, 10$-min GBF treatment with impeller of 2-mm-dia. aperture $\mathbf{d}$ and spectral results $\mathbf{e}, \mathbf{f}$ of EDS analysis for $A$ - and $B$-positions in a

related to the positive buoyancy, $P$ and drag force, $F$, which arise from the difference between the density of a gas bubble and the melt and the viscosity of a melt and the size of gas bubble, respectively. These terms can be expressed by the following Eqs. (1) and (2), respectively.

$P=(4 / 3 \pi) r^{3}\left(\rho_{\text {melt }}-\rho_{\text {gasbubble }}\right) g$,

where $r$ and $\rho_{\text {gas bubble }}$ are the radius and density of a formed gas bubble, and $\rho_{\text {melt }}$ and $g$ are the melt density and the gravity acceleration, respectively.

$F=6 \pi \eta r U$, where $\eta$ and $U$ are the viscosity and buoyant speed, respectively.

Assuming the gas bubble buoy to the surface of the melt at a constant speed, $U$ can be expressed as the following [2]

$U=\left(2 r^{2} / 9 \eta\right)\left(\rho_{\text {melt }}-\rho_{\text {gasbubble }}\right) g$.

In Eq. (3), the buoyant speed of the gas bubble increases with the size of gas bubble. From this, it can predict that the degassing efficiency decreases proportionally as the duration time for absorbing the dissolved hydrogen gas decreases, i.e. as the buoyant speed increases. In the 

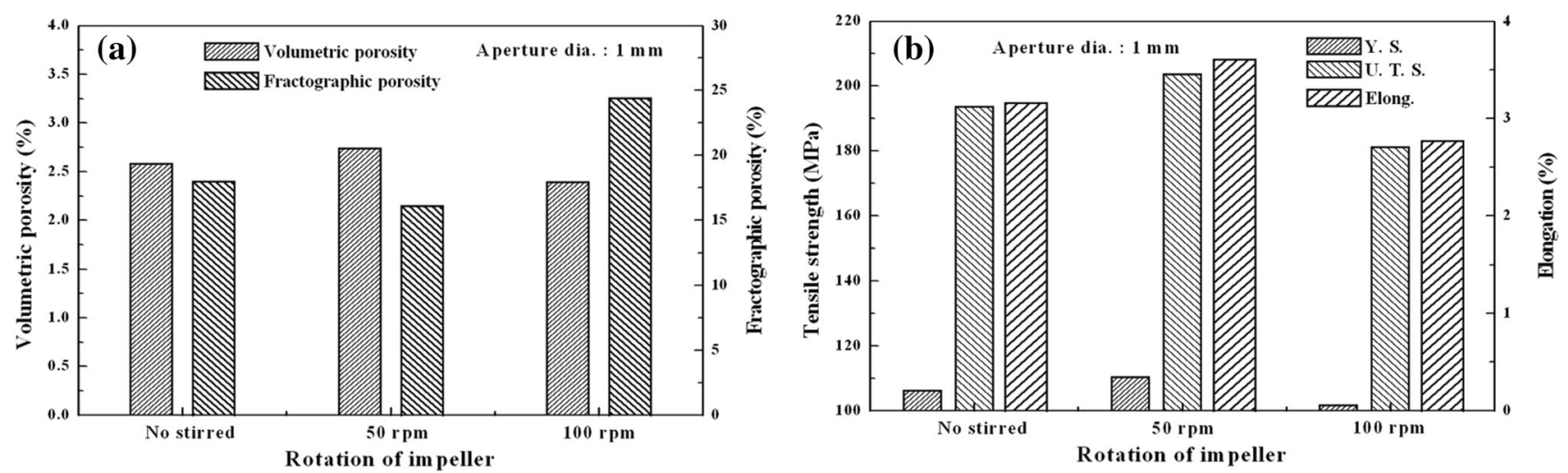

Fig. 8 Comparison of the porosity $\mathbf{a}$ and the tensile properties $\mathbf{b}$ with melt stirring by rotation of impeller
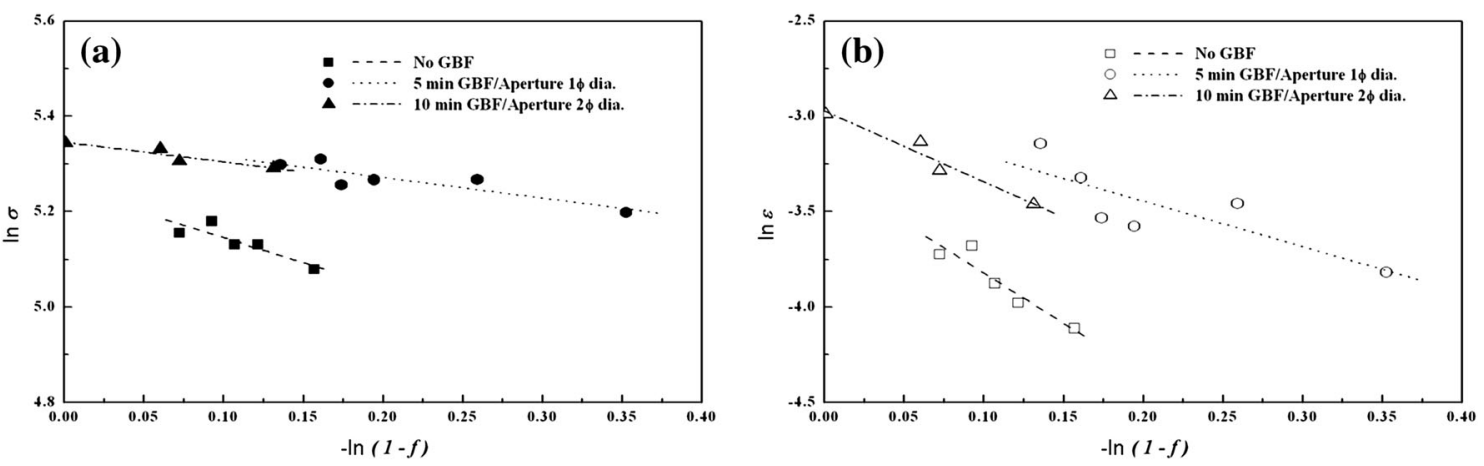

Fig. 9 Defect susceptibility of the tensile strength a and elongation $\mathbf{b}$ for the microporosity variation with regard to the GBF treatment conditions

Table 3 Defect susceptibility of the tensile properties to microporosity variation and maximum values of the tensile properties achievable under defect-free conditions

\begin{tabular}{|c|c|c|c|c|c|}
\hline \multirow[t]{2}{*}{ Treatment } & \multicolumn{2}{|c|}{ Defect susceptibility } & \multicolumn{2}{|c|}{ Maximum values achievable in defect-free condition $(f=0)$} & \multirow{2}{*}{$\begin{array}{l}\text { Strain-hardening } \\
\text { exponent }\end{array}$} \\
\hline & UTS & Elongation & UTS (MPa) & Elongation $(\%)$ & \\
\hline No GBF & 1.03 & 5.27 & 190.2 & 3.7 & 0.23 \\
\hline $10 \mathrm{~min}(2 \mathrm{~mm}$ diameter $)$ & 0.42 & 3.72 & 209.8 & 5.1 & 0.26 \\
\hline $5 \mathrm{~min}$ (1 $\mathrm{mm}$ diameter $)$ & 0.43 & 2.38 & 212.3 & 5.1 & 0.25 \\
\hline
\end{tabular}

A356 alloy under as-cast condition

present study, the buoyant speed for a GBF treatment with impeller of 2-mm-diameter aperture is relatively high compared to that for the 1-mm aperture, and thus the degassing efficiency for a 1-mm aperture is greater than for the 2-mm aperture. From Fig. 6, it can be noted that the optimal degassing time is shortened from 10 to $15 \mathrm{~min}$ to approximately $5 \mathrm{~min}$ with the decrease of the aperture size from 2 to $1 \mathrm{~mm}$. Thus, excepting additional contributions such as the inclusion of bifilm oxides, the optimal degassing condition can be proposed from the correlation between the buoyant speed and the absorbing capacity in terms of the size distribution of gas bubbles and the viscosity of a melt [12].

\subsection{Microstructural Refinement and Inclusion of Bifilm Oxides}

As shown in Fig. 3 and Table 2, microstructural features such as the individual size of eutectic Si particles and the SDAS are remarkably refined through GBF treatment. This also influences the tensile properties of the as-cast alloys. As shown in Figs. 5 and 6, the tensile properties of the 
alloys degassed with a 1-mm-diameter aperture are not deteriorated by degassing treatment beyond the optimal conditions, despite the increase of the fractographic porosity by GBF treatment. Furthermore, the nominal value of the yield strength is increased over about $5 \mathrm{MPa}$ despite a practical deterioration of UTS beyond 5-min GBF. This increase of yield strength arises from a remarkable refinement of microstructural features such as the grain size and SDAS.

However, even though the several studies for the characterisation of the microstructure and porosity variation in aluminium melt have been reported up to recent [17-19], the microstructural refinement by GBF treatment has been rarely reported in the previous studies [8]. Under the turbulent convection of the melt, the inclusion of the oxide particles formed from additional exposure or the alloy element dissolved out from the manufacturing equipment such as the impeller and skimmer can be taken into account as a potent reason for microstructural transition during GBF treatment. In the present study, it was observed that the surface of the impeller near the gas inlet to a melt was slightly eroded during experiments. Table 4 shows the difference of chemical composition for several elements before and after GBF treatment. Thus, it can consider that the introduction of alloy elements such as $\mathrm{Fe}, \mathrm{Cr}$ and $\mathrm{Ni}$ into the aluminium melt may provide a potential nucleation site by the formation of fine intermetallic compounds, although a detailed further study for the grain refinement accompanying with the GBF process is required.

On the other hand, some research reported that the mechanical properties of degassing-treated alloys may be degraded by the inclusion of dross and oxide particles falling into the melts using a rotation-type impeller, while the nominal level of microporosity can be decreased by the degassing treatment [2-6]. In particular, the inclusion of bifilm-type oxides affects practically the deterioration of the mechanical properties of an alloy, is mainly induced through the oxidation on the interface between the melt and a rotary-type impeller, the melt stirring by explosion of buoyant gas bubbles and the exposure in the transport/ pouring process $[1,10-12]$. In the present study, the inclusion of oxide particles falling into a melt on base condition and the effective removal by GBF treatment could be confirmed by SEM observation and EDS analysis as shown in Fig. 7.

Table 4 Variation of typical chemical element with GBF treatment

\begin{tabular}{lllllll}
\hline Treatment & $\mathrm{Si}$ & $\mathrm{Mg}$ & $\mathrm{Fe}$ & $\mathrm{Ni}$ & $\mathrm{Cr}$ & $\mathrm{Al}$ \\
\hline No GBF & 7.31 & 0.33 & 0.291 & 0.042 & 0.026 & $\mathrm{Bal}$. \\
15-min GBF & 7.25 & 0.43 & 1.08 & 0.178 & 0.171 & $\mathrm{Bal}$. \\
\hline
\end{tabular}

Nevertheless, the present study shows that it could not estimate the inclusion of oxide particles, which exist at very low concentrations. Figure 10 shows that the diffraction peaks of the aluminium oxide series are not detected without regard to GBF treatment, although the diffraction peaks for $\mathrm{Al}$ and $\mathrm{Si}$ are clearly detected. However, the experimental results on SEM fractography analysis and tensile test indicate that the inclusion of even a small amount of bifilm oxide, which is not detected by conventional XRD analysis, is enough to degrade the mechanical properties of aluminium castings [1, 10-12].

\subsection{Defect Susceptibility}

Gokhale et al. $[13,14]$ suggested that the dependence can be empirically described as a power law relationship in terms of the defect susceptibility of the tensile elongation to microporosity variation, $a$ and a maximum value achievable in a defect-free condition, $\varepsilon_{\mathrm{o}}$ as in the following Eq. (4):

$e=e_{o}(1-f)^{a}$,

where $\varepsilon$ is the elongation of a material with a microporosity $f$.

In addition, the UTS, $\sigma$ is the UTS of a material with microporosity, $f$ can be expressed as a power law dependence on the microporosity variation as the following equation $[15,16]$

$\sigma=\sigma_{o}(1-f)^{b}$,

where $\sigma_{\mathrm{o}}$ is the maximum UTS achievable in a defect-free material and $b$ is the defect susceptibility of UTS to microporosity variation.

As shown in Fig. 9 and Table 3, the defect susceptibility of UTS and elongation to microporosity variation for A356 alloy can be practically improved through the use of the optimal GBF treatment, with a notable increase in the

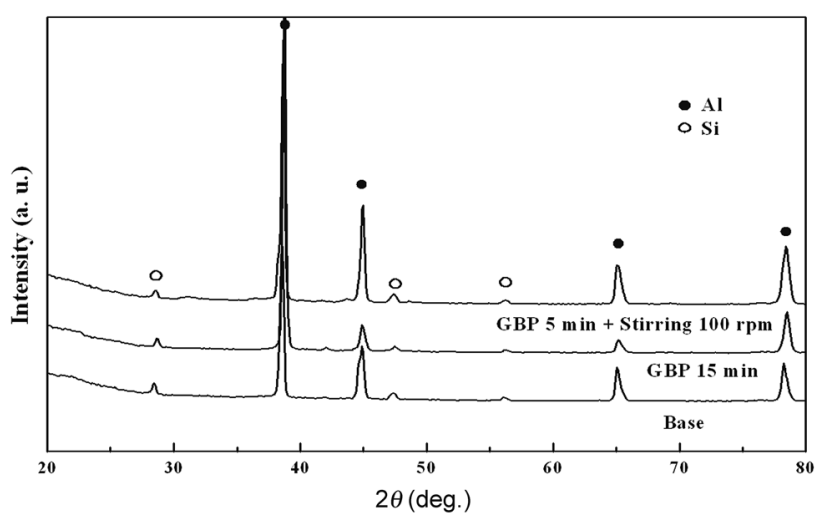

Fig. 10 Comparison of XRD patterns between the GBF and nonGBF-treated alloys 
maximum values of UTS and elongation achievable under defect-free conditions $(f=0)$.

With the assumption that a material with microporosity $f$ at a fixed condition of the strength coefficient, the strain rate and strain rate sensitivity are plastically deformed by the power law relation $\sigma=K \varepsilon^{n} \varepsilon^{m}$ under local equilibrium, the UTS and elongation are practically increased as the strain-hardening exponent increases [20].

The constitutive description for the defect susceptibility of tensile elongation to microporosity variation, $a$ can be proposed through the substitution with Eq. (4) to the power law relationship, as the following Eq. (6).

$a=-(1 / n)\left[\left(\varepsilon_{h}-\varepsilon_{i}\right)+\ln (1-f)\right] / \ln (1-f)$,

where $\varepsilon_{h}$ and $\varepsilon_{i}$ are the far field strain from void region and near field to void region, respectively, and $n$ and $m$ are the strain-hardening exponent and strain rate sensitivity, respectively [20].

Likewise, the defect susceptibility of UTS to microporosity variation, $b$ can also be described as following Eq. (7), with the expansion of the numerical formula to the empirical relationship for the defect susceptibility of the UTS (Eq. (5)).

$b=-\left[\left(\varepsilon_{h}-\varepsilon_{i}\right) / \ln (1-f)+1\right]$.

Equations (6) and (7) indicate that the defect susceptibility of the tensile properties is fundamentally related to the strain-hardening exponent and the difference between the near field strain and the far field strain to the void region $[16,20]$. In addition, the maximum values achievable under defect-free conditions are increased with the strain-hardening exponent.

Thus, the defect susceptibility of the tensile properties to microporosity variation can be practically improved through an interaction that also triggers the increase of strain-hardening exponent, the refinement of the microstructure and the decrease of microporosity level on an optimal GBF treatment.

\section{Conclusions}

(1) The volumetric porosity of gravity-cast A356 alloy is wholly decreased from $3.5 \%$ with no GBF treatment to $2.5 \%$ with the degassing time in the GBF process. In terms of the variation of fractographic porosity, the optimal GBF conditions practically depend upon the degassing time and the aperture size of the gas inlet, exhibiting an increasing trend with the degassing time under optimal GBF conditions by increasing gas inlet aperture size.

(2) The average values of UTS and elongation under optimal GBF conditions exhibit an improvement of $30 \mathrm{MPa}$ and $2.0 \%$, respectively, in comparison with no GBF treatment. The dependence of the tensile properties on microporosity variation can be described accurately in terms of the fractographic porosity, but not the variation of volumetric porosity.

(3) The maintenance of a melt beyond optimal GBF conditions can be induced by the increase of the fractographic porosity, but the tensile properties are not practically degraded because of a notable microstructural refinement under GBF treatment.

(4) The bifilm oxide particles which can be effectively removed by GBF treatment may be induced into a melt through GBF treatment beyond optimal conditions or with exceptional treatments such as melt stirring, and these bifilm inclusions have an obvious contribution to the deterioration of the tensile properties of GBF-treated alloys, equivalent to the existence of micro-voids.

Acknowledgments This research was supported by the General Researcher Program through the National Research Foundation of Korea (NRF) and funded by the Ministry of Education, Science and Technology (2010-0022284) and was also supported by the Development Program for Industrial Core-Technology through the Korea Evaluation Institute of Industrial Technology (KEIT) and funded by the Ministry of Trade, Industry and Energy (10048817).

\section{References}

[1] J. Campbell, Complete Casting Handbook (Butterwoth-Heinemann, Oxford, 2011), p. 94

[2] L. Zhao, Y. Pan, H. Liao, Q. Wang, Mater. Lett. 66, 328 (2012)

[3] T.S. Shih, K.Y. Weng, Mater. Trans. 45, 1852 (2004)

[4] T.S. Shih, K.Y. Wen, Mater. Trans. 46, 263 (2005)

[5] L.W. Huang, P.W. Wang, T.S. Shih, J.H. Liou, Mater. Trans. 43, 2913 (2002)

[6] J. Wannasin, R.A. Martinezb, M.C. Flemings, Scr. Mater. 55, 115 (2006)

[7] G.I. Eskin, Ultrason. Sonochem. 2, 137 (1995)

[8] A.R. Naji Meidani, M. Hasan, J. Mater. Proc. Technol. 147, 313 (2004)

[9] H. Xu, X.G. Jian, T.T. Meeka, Q.Y. Han, Mater. Lett. 58, 3669 (2004)

[10] D. Dispinar, J. Campbell, Mater. Sci. Eng. A 528, 3860 (2011)

[11] D. Dispinar, S. Akhtar, A. Nordmark, M.D. Sabatino, L. Arnberg, Mater. Sci. Eng. A 527, 3719 (2010)

[12] J.T. Staley Jr., M. Tiryakioglu, J. Campbell, Mater. Sci. Eng. A 460-461, 324 (2007)

[13] A.M. Gokhale, G.R. Patel, Scr. Mater. 52, 237 (2005)

[14] S.G. Lee, G.R. Patel, A.M. Gokhale, A. Sreeranganathan, M.F. Horstemeyer, Mater. Sci. Eng. A 427, 255 (2006)

[15] C.D. Lee, Mater. Sci. Eng. A 488, 296 (2008)

[16] C.D. Lee, K.S. Shin, Mater. Sci. Eng. A 599, 223 (2014)

[17] E. Escobar de Obaldia, S.D. Felicelli, J. Mater. Proc. Technol. 191, 265 (2007)

[18] V. Bohlooli, M.S. Mahalli, S.M.A. Boutorabi, Acta Metall. Sin. (Engl. Lett.) 26, 85 (2013)

[19] Z.Q. Hu, X.J. Zhang, S.S. Wu, Acta Metall. Sin. (Engl. Lett.) 28, 1344 (2015)

[20] A.K. Ghosh, Acta Metall. 25, 1413 (1977) 